\title{
Matrix Microstructure and Its Micro-Analysis of Constituent Phases in As-Cast Fe-Cr-C-V Alloys
}

\author{
Mirjana Filipovic, Endre Romhanji, Zeljko Kamberovic and Marija Korac \\ Department of Metallurgical Engineering, Faculty of Technology and Metallurgy, University of Belgrade, \\ Karnegijeva 4, 11120 Belgrade, Serbia
}

\begin{abstract}
The as-cast matrix microstructure in 19 mass $\% \mathrm{Cr}-2.8$ mass $\% \mathrm{C}$ white cast iron with up to 4.7 mass $\% \mathrm{~V}$ additions has been studied. Type and degree of the austenite transformation in the course of cooling after solidification in Fe-Cr-C-V alloys appeared to be dependent on the content of carbon and other alloying elements. Results obtained by EDS analysis of the phases in the tested Fe-Cr-C-V alloys indicated that vanadium is present in both matrix and carbide. Increasing the vanadium content in the alloy, its concentration increases in the matrix, whereas the concentration of carbon decreases. The precipitation kinetic of carbides in austenite was found dependent on the vanadium content. The volume fraction of $\mathrm{M}_{23} \mathrm{C}_{6}$ carbides was larger when the vanadium content was higher. TEM analysis revealed that both twinned and dislocation type martensites were present around secondary carbides. The transformation of austenite into martensite in the Fe-C-Cr-V alloys seems to be closely related to the precipitation of secondary carbides. [doi:10.2320/matertrans.M2009002]
\end{abstract}

(Received January 6, 2009; Accepted July 23, 2009; Published September 25, 2009)

Keywords: as-cast matrix microstructure, transformation of austenite, secondary $M_{23} C_{6}$ carbides, martensite, iron-chromium-carbonvanadium alloys

\section{Introduction}

White cast irons have been used for abrasion resisting applications. So, the primary requirement was a good abrasion resistance, and only a modest resistance to brittle fracture. Most improvements in abrasion resistance are accompanied by lower toughness, due to the higher content of eutectic carbide. Nevertheless, a range of properties can be obtained by matrix variations to obtain optimum combinations of wear resistance and resistance to premature failure. Such a change can be achieved by alloying and/or heat treatment. ${ }^{1-5)}$

Possibilities for improving the properties of a high chromium white iron, using explicitly carbidizing elements as tungsten, ${ }^{6,7)}$ niobium, ${ }^{6,8-12)}$ vanadium, ${ }^{5-7,12-16)}$ titanium, ${ }^{8,12,17)}$ and boron ${ }^{18)}$ were studied in a great deal. Vanadium appeared to be of special interest, due to its double effect, on both the matrix structure and stereological characteristics of carbide.

In this work, the influence of vanadium content on the ascast matrix microstructure of high chromium white iron is examined.

\section{Experimental Procedure}

The chemical composition of tested alloys is listed in Table 1. Induction furnace was used for melting, and $200 \mathrm{~mm}$ long and $30 \mathrm{~mm}$ in diameter bars were cast in sand moulds. Samples for structural analysis were cut from the cast bars.

The microstructure was examined using conventional optical microscopy (OM) and transmission electron microscopy (TEM). Samples for optical microscope examinations were prepared using standard metallographic technique (etched with picric acid solution $(1 \mathrm{~g})$ in methanol $(100 \mathrm{~mL})$ by adding $5 \mathrm{~mL}$ of hydrochloric acid). The volume fraction of the eutectic carbides were determined using image analyzer. Discs for TEM examinations were prepared by using a twinjet electropolisher. These samples were examined at $200 \mathrm{kV}$ in a JEOL-2000FX transmission electron microscope. The chemical composition of the matrix was determined using energy dispersive X-ray spectroscopy (EDS). Measured values are the averge ones obtained from the mixture of practical matrix and secondary carbides (because the electron beam of EDS picks up the secondary carbides particles).

The $\mathrm{Cr} K_{\alpha}$ radiation has been used for measuring the amount of retained austenite by means of X-rays, as it is considered to be more appropriate for structures containing greater amounts of carbides (in order to increase the dispersion, if there are interference peaks, for example). ${ }^{19)}$ A continuously rotating/tilling specimen holder was used to eliminate the effect of the preferred orientation of the columnar structure, which has been shown to affect the results (as it has been described in detail in Ref. 20)). At a scanning rate of $1^{\circ} \mathrm{min}^{-1}$, the integrated intensities under the peaks (200) $\alpha,(220) \alpha,(220) \gamma$ and (331) $\gamma$ were measured by a diffractometer.

\section{Results}

The as-cast microstructure of examined alloys consists of primary austenitic dendrites and eutectic with $\mathrm{M}_{7} \mathrm{C}_{3}$ carbides, and austenite (Fig. 1). Changes in the matrix microstructure over the examined range of vanadium levels are illustrated in Fig. 1.

The primary austenite in $\mathrm{Fe}-\mathrm{Cr}-\mathrm{C}$ alloy, with no vanadium addition, remains stable at cooling down to room temperature (Fig. 1(a)). Dislocations revealed in the austenite (Fig. 2(a)), and in the region of primary and eutectic austenite, arround the eutectic carbides, twinned martensite detected (Fig. 2(b)). In a less extent, martensite having a dislocation substructure can be noticed just around the twinned martensite (Fig. 2(b)).

Inhomogeneous distribution of dark particles was visible in the austenite of $\mathrm{Fe}-\mathrm{Cr}-\mathrm{C}-\mathrm{V}$ alloy containing $2.02 \% \mathrm{~V}$ (Fig. 1(b)). Particles in the matrix (Fig. 1(b)) were identified as $\mathrm{M}_{23} \mathrm{C}_{6}$ type carbides (Fig. 3). 
Table 1 Chemical composition of tested Fe-C-Cr-V alloys.

\begin{tabular}{|c|c|c|c|c|c|c|c|c|c|c|}
\hline \multirow{2}{*}{ Alloy } & \multicolumn{10}{|c|}{ Chemical composition (mass\%) } \\
\hline & $\mathrm{C}$ & $\mathrm{P}$ & $S$ & $\mathrm{Si}$ & $\mathrm{Mn}$ & Mo & $\mathrm{Cu}$ & $\mathrm{Ni}$ & $\mathrm{Cr}$ & $\mathrm{V}$ \\
\hline 1 & 2.89 & 0.025 & 0.061 & 0.85 & 0.71 & 0.48 & 0.99 & 0.100 & 19.03 & 0.0012 \\
\hline 3 & 2.88 & 0.025 & 0.061 & 0.86 & 0.72 & 0.42 & 0.98 & 0.098 & 18.89 & 0.49 \\
\hline 4 & 2.92 & 0.025 & 0.061 & 0.85 & 0.75 & 0.43 & 1.01 & 0.098 & 19.04 & 1.19 \\
\hline 5 & 2.87 & 0.024 & 0.063 & 0.87 & 0.73 & 0.44 & 1.01 & 0.099 & 18.92 & 2.02 \\
\hline 6 & 2.91 & 0.027 & 0.061 & 0.84 & 0.73 & 0.44 & 1.00 & 0.096 & 19.05 & 3.28 \\
\hline 7 & 2.93 & 0.026 & 0.062 & 0.83 & 0.74 & 0.43 & 1.01 & 0.098 & 19.07 & 4.73 \\
\hline
\end{tabular}
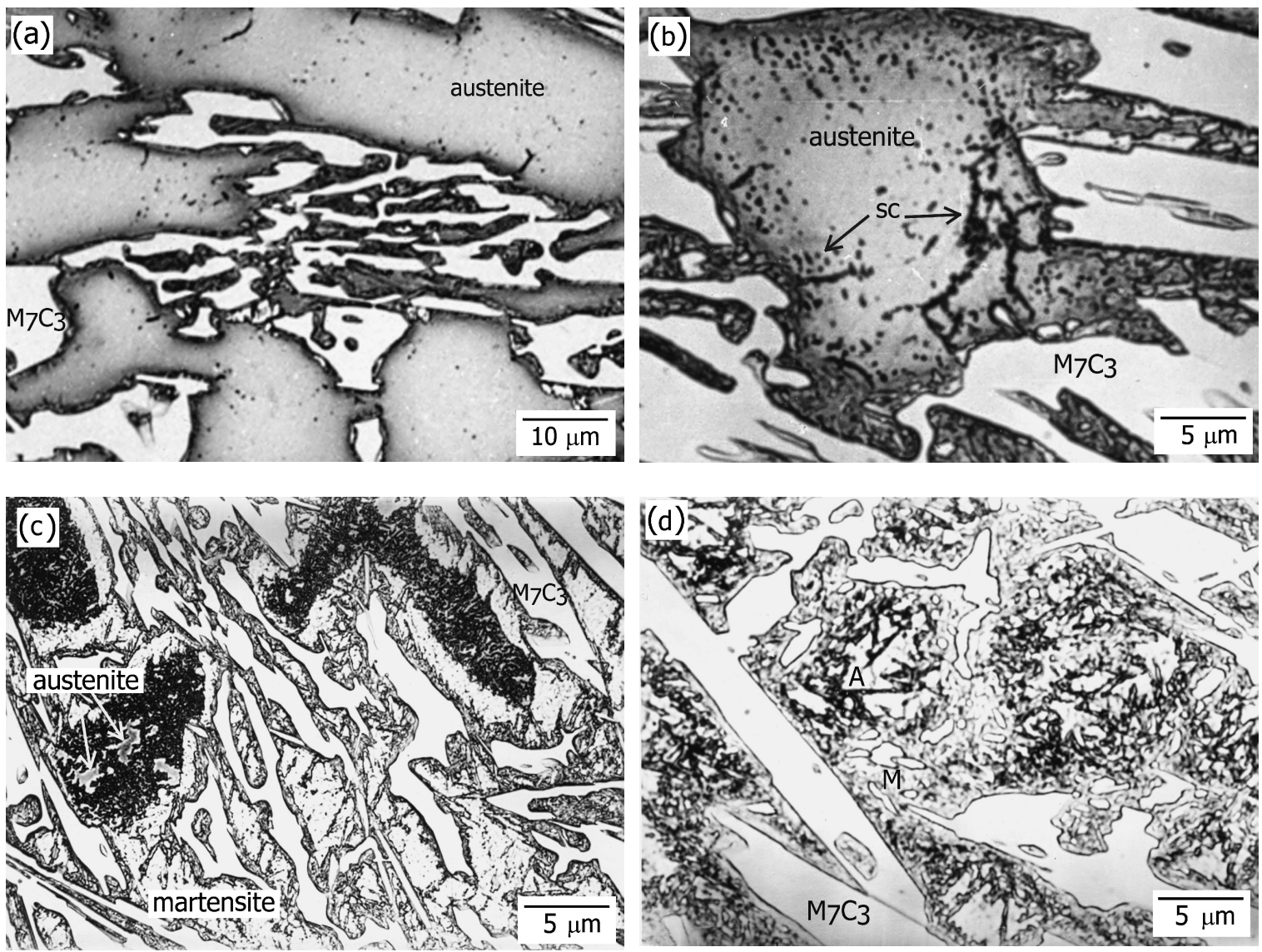

Fig. 1 Optical micrographs of Fe-Cr-C alloy (a) and Fe-Cr-C-V alloy containing 2.02\% V (b), 3.28\% V (c), 4.73\% V (d).
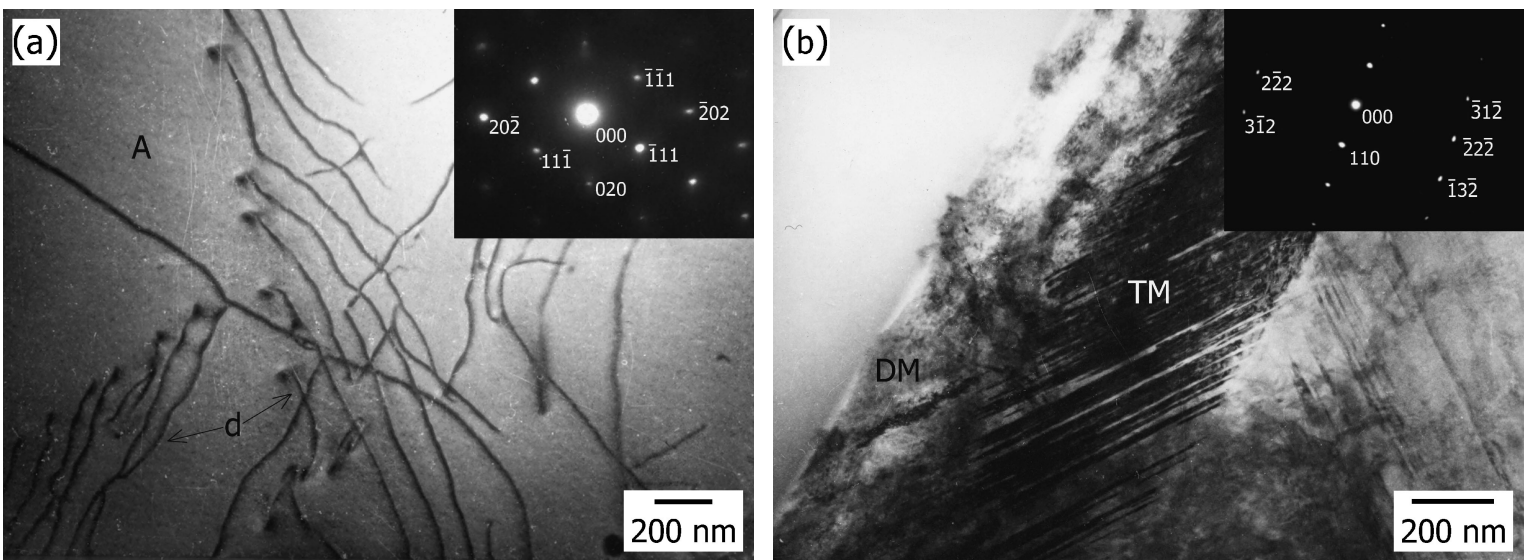

Fig. 2 Transmission electron micrographs of $\mathrm{Fe}-\mathrm{Cr}-\mathrm{C}$ alloy showing: (a) austenite and selected-area diffraction pattern (in the corner) from the region in this micrograph, showing a [101] zone axis, (b) region of dendrite near to a eutectic carbide and selected-area diffraction pattern (in the corner) from the region in this micrograph showing a [112] zone axis, (markings on the micrographs: Aaustenite, d-dislocations, TM-twinned martensite, DM-dislocation martensite). 


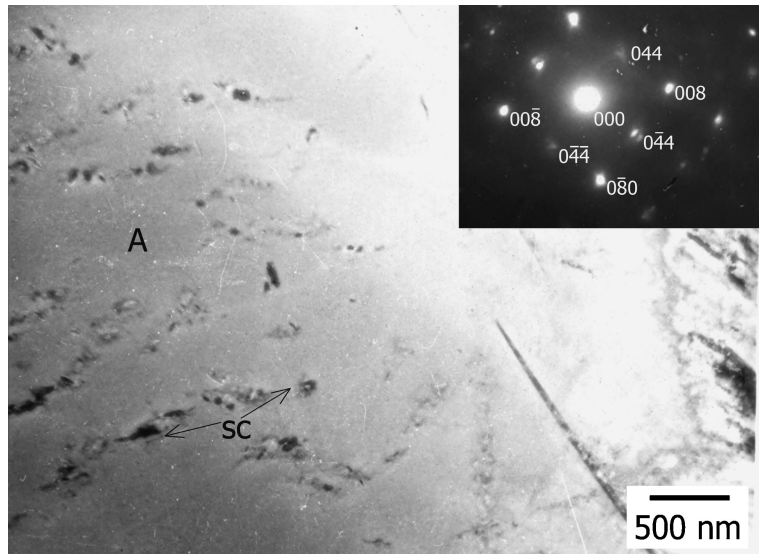

Fig. 3 Transmission electron micrograph of the Fe-Cr-C-V alloy containing $2.02 \% \mathrm{~V}$ showing secondary carbides and selected-area diffraction pattern (in the corner) from the region in this micrograph showing a [100] zone axis, (markings on the micrographs: A-austenite, $\mathrm{sc}-\mathrm{M}_{23} \mathrm{C}_{6}$ carbide)

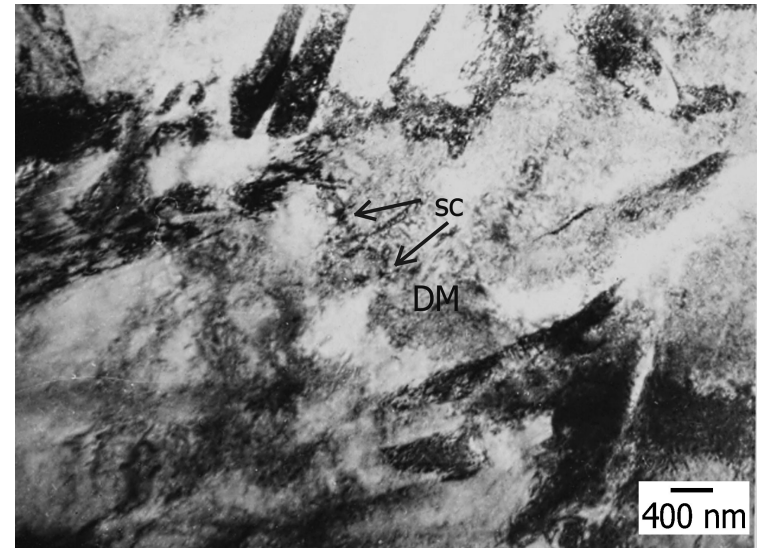

Fig. 5 Transmission electron micrographs of the Fe-Cr-C-V alloy containing $4.73 \% \mathrm{~V}$ showing secondary carbides and martensite (markings on the micrographs: $\mathrm{sc}-\mathrm{M}_{23} \mathrm{C}_{6}$ carbide, DM-dislocation martensite).
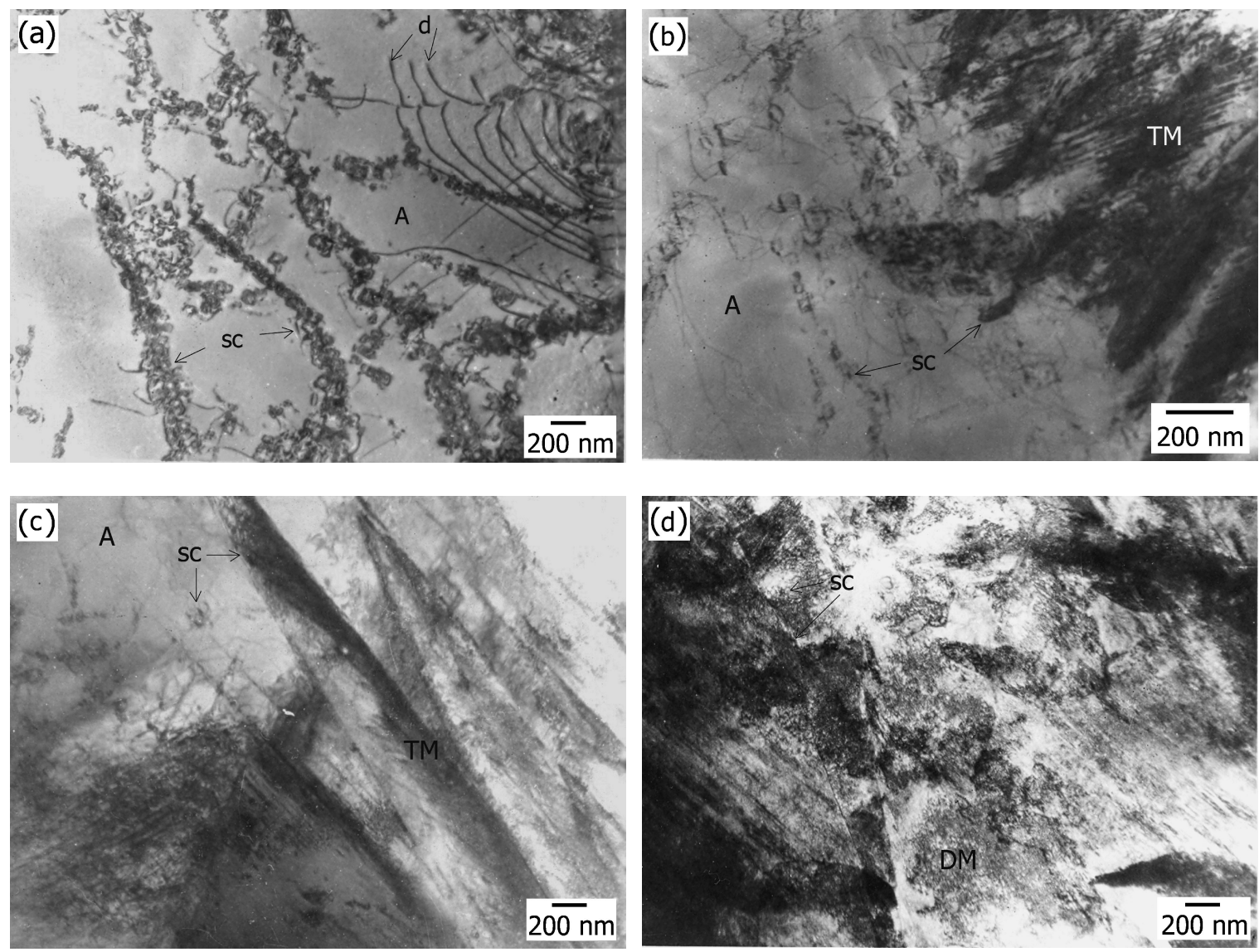

Fig. 4 Transmission electron micrographs of the Fe-Cr-C-V alloy containing 3.28\% V showing: (a) secondary carbides, (b) and (c) secondary carbides and martensite (d) region of dendrite near to a eutectic carbide (markings on the micrographs: $\mathrm{A}$-austenite, $\mathrm{sc}_{-} \mathrm{M}_{23} \mathrm{C}_{6}$ carbide, d-dislocations, TM-twinned martensite, DM-dislocation martensite).

A large number of fine particles of $\mathrm{M}_{23} \mathrm{C}_{6}$ carbide were present in the austenite of high chromium white iron containing $3.28 \% \mathrm{~V}$ (Fig. 1(c)). Transformation of austenite can be seen in a larger portion of the dendrites (Fig. 1(c)). Dislocations or martensite are present all around the secondary carbides (Figs. 4(a)-4(c)). The presence of secondary carbides is also noticed at the austenite subgrain boundaries (Fig. 4(d)). Around the carbide particles, along the interface between the dendrite and the eutectic $\mathrm{M}_{7} \mathrm{C}_{3}$ carbides, both twinned and dislocation martensite was identified (Fig. 4(d)).

Voluminuous austenite transformation was found in the microstructure of $\mathrm{Fe}-\mathrm{Cr}-\mathrm{C}-\mathrm{V}$ alloy containing $4.73 \% \mathrm{~V}$ (Fig. 1(d)). TEM analysis showed that the product of this transformation is martensite with predominantly dislocation substructure (Fig. 5). 
Table 2 Chemical composition of the as-cast matrix in Fe-C-Cr-V alloys.

\begin{tabular}{|c|c|c|c|c|c|c|c|c|c|}
\hline \multirow[b]{2}{*}{ Alloy } & \multirow{2}{*}{$\begin{array}{c}\mathrm{V} \text { in } \\
\text { alloy } \\
\text { (mass\%) }\end{array}$} & \multicolumn{8}{|c|}{ Chemical composition of the matrix (mass $\%$ ) } \\
\hline & & $\mathrm{C}$ & $\mathrm{Si}$ & $\mathrm{Mn}$ & Mo & $\mathrm{Cu}$ & $\mathrm{Cr}$ & $\mathrm{Fe}$ & $\mathrm{V}$ \\
\hline 2 & 0.12 & $1.35-1.56$ & $0.82-0.93$ & $0.63-0.68$ & $0.24-0.34$ & $1.43-1.81$ & $11.76-12.89$ & $82.07-83.16$ & $0.014-0.015$ \\
\hline 4 & 1.19 & $1.01-1.31$ & $0.95-1.12$ & $0.78-0.82$ & $0.22-0.38$ & $1.46-1.82$ & $11.20-12.71$ & $82.92-83.24$ & $0.341-0.346$ \\
\hline 6 & 3.28 & $0.65-0.94$ & $0.88-0.97$ & $0.72-0.81$ & $0.17-0.35$ & $1.74-1.96$ & $11.51-12.42$ & $81.37-82.84$ & $1.26-1.29$ \\
\hline 7 & 4.73 & $0.54-0.79$ & $0.96-1.04$ & $0.78-0.81$ & $0.32-0.47$ & $1.71-1.87$ & $11.62-12.16$ & $81.14-82.35$ & $1.84-1.89$ \\
\hline
\end{tabular}
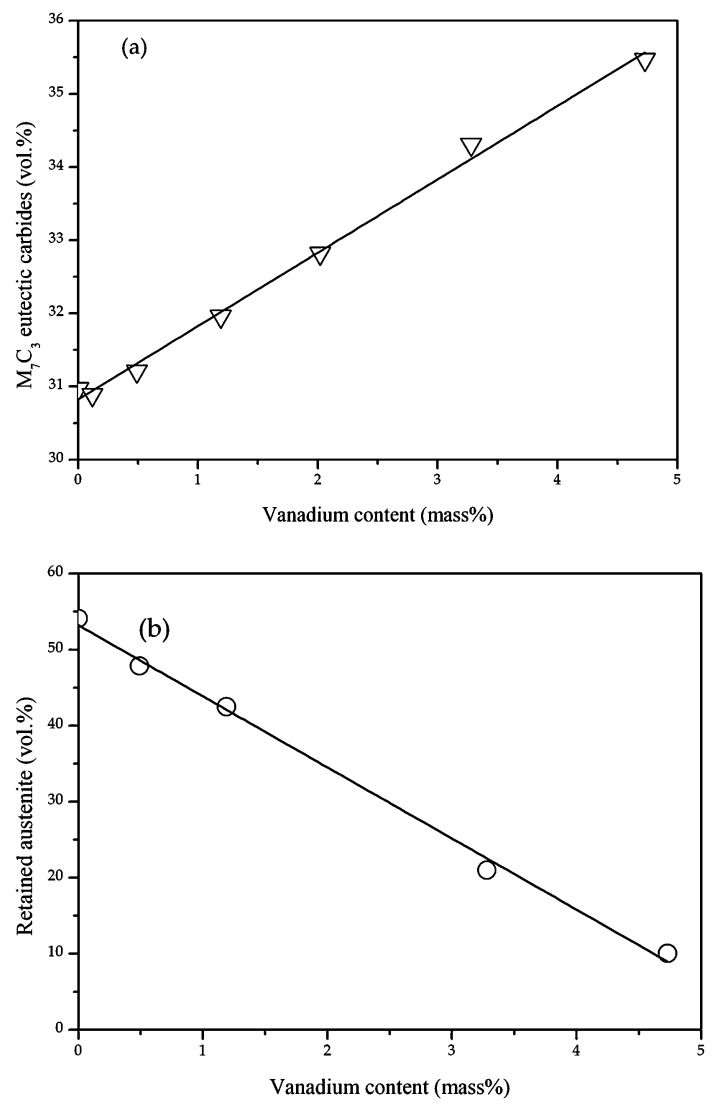

Fig. 6 Volume fraction of $\mathrm{M}_{7} \mathrm{C}_{3}$ eutectic carbide (a) and of retained austenite (b) as a function of vanadium content in the alloy.

Results obtained by EDS analysis of the as-cast matrix in tested Fe-Cr-C-V alloys are given in Table 2. The carbon content was calculated by balancing with the other elements. These results (Table 2) indicate that only a part of added vanadium is present in the matrix, while the rest should be in the carbides. At the same time, with increasing the vanadium content the concentration of carbon decreases in austenite.

The volume fraction of $\mathrm{M}_{7} \mathrm{C}_{3}$ carbides is increased (Fig. 6(a)), whereas the amount of retained austenite is decreased (Fig. 6(b)) with increasing the vanadium content.

\section{Discussion}

Vanadium was found to affect the transformation of austenite in as-cast condition of a tested Fe-Cr-C-V alloys. With increasing vanadium content, the volume fractions of secondary carbides and martensite increase (Fig. 1), and the amount of retained austenite decreases.
Austenite remains as a metastable phase at room temperature in $\mathrm{Fe}-\mathrm{Cr}-\mathrm{C}$ alloy with no vanadium addition (Figs. 1(a) and 2(a)), due to the high amount of carbon and alloying elements that lowers the martensite transformation start temperature $\mathrm{M}_{\mathrm{s}}$.

It has been suggested by several authors ${ }^{2,5,12,17)}$ that during eutectic solidification the $\mathrm{M}_{7} \mathrm{C}_{3}$ carbide, which grows along the austenite, absorbs carbon from its surroundings and a narrow area at the austenite/carbide interphase becomes impoverished in it. The lack of carbon in these zones of austenite increases the $M_{s}$ temperature which allows these areas of austenite to transform into martensite during subsequent cooling. TEM observation revealed a mainly twinned but also dislocation type martensite in these regions (Fig. 2(b)). With increasing vanadium content in the examined $\mathrm{Fe}-\mathrm{Cr}-\mathrm{C}-\mathrm{V}$ alloys, the volume fraction of dislocation martensite increases (Figs. 4(d) and 5) as a consequence of lower carbon content in the austenite.

Type and degree of transformation of austenite in the course of cooling after solidification in $\mathrm{Fe}-\mathrm{Cr}-\mathrm{C}-\mathrm{V}$ alloys, as in $\mathrm{Fe}-\mathrm{Cr}-\mathrm{C}$ alloys, depend on chemical composition of austenite, i.e. on the content of carbon and other alloying elements.

The chemical composition of austenite changes by changing the vanadium content in high chromium iron. Adding more $\mathrm{V}$ into the tested $\mathrm{Fe}-\mathrm{Cr}-\mathrm{C}-\mathrm{V}$ type alloys was followed with higher vanadium content in the austenite as a normal consequence of its wide solubility reange in the $\gamma$-solid solution. The lower carbon content experienced in the matrix in alloy with higher vanadium content was assumed to be related to the larger amount of eutectic with $\mathrm{M}_{7} \mathrm{C}_{3}$ carbides (Fig. 6(a)).

At temperatures below solidus, in the course of further cooling after solidification, $\mathrm{M}_{23} \mathrm{C}_{6}$ carbides precipitate in austenite (Fig. 3), mainly in areas with lower carbon content. Due to heterogeneity of the matrix composition, precipitation is heterogenous, and in alloys with vanadium content lower than $2 \%$ they were predominantly located in the surface dendrite zone (Fig. 1(b)).

Carbides precipitation kinetic in austenite of $\mathrm{Fe}-\mathrm{Cr}-\mathrm{C}-\mathrm{V}$ alloys depends on the vanadium content in the alloy. In spite of the vanadium content increase in the austenite matrix, part of the added vanadium was locked in the precipitated $\mathrm{M}_{23} \mathrm{C}_{6}$ carbides, whose volume fraction increased in alloys with higher vanadium content.

The transformation of austenite into martensite in the $\mathrm{Fe}-\mathrm{C}-\mathrm{Cr}-\mathrm{V}$ alloys is closely related to the precipitation of secondary carbides. Precipitation of $\mathrm{M}_{23} \mathrm{C}_{6}$ carbides minimizes the carbon and chromium content in matrix, and 
increases the $\mathrm{M}_{\mathrm{s}}$ temperature. The degree of martensitic transformation is determined by the amount of precipitated carbides, i.e., depends on the austenite composition.

\section{Conclusions}

Vanadium changed the transformation characteristics of austenite in as-cast condition in the $\mathrm{Fe}-\mathrm{C}-\mathrm{Cr}-\mathrm{V}$ type alloys. Type and degree of transformation of austenite during cooling, after solidification, depends on the chemical composition of austenite, i.e. on the content of carbon an other alloying elements. Results obtained by EDS analysis of the as-cast matrix in tested $\mathrm{Fe}-\mathrm{Cr}-\mathrm{C}-\mathrm{V}$ alloys indicated that by increasing the vanadium content, its concentration increases in the matrix, whereas the concentration of carbon decreases.

Carbides precipitation kinetic in austenite of $\mathrm{Fe}-\mathrm{Cr}-\mathrm{C}-\mathrm{V}$ alloys depends on the vanadium content in the alloy. The volume fraction of $\mathrm{M}_{23} \mathrm{C}_{6}$ carbides was larger when the vanadium content was higher.

The transformation of austenite into martensite in the Fe-C-Cr-V alloys is closely related to the precipitation of secondary carbides. Precipitation of $\mathrm{M}_{23} \mathrm{C}_{6}$ carbides minimizes the carbon and chromium content in matrix, and increases the $\mathrm{M}_{\mathrm{s}}$ temperature. The degree of martensitic transformation is determined by the amount of precipitated carbides, i.e., depends on the austenite composition.

\section{REFERENCES}

1) J. Dodd and J. L. Parks: Met. Forum 3 (1980) 3-27.

2) Z. Sun, R. Zuo, C. Li, B. Shen, J. Yan and S. Huang: Mater. Charact. 53 (2004) 403-409.

3) S. K. Hann and J. D. Gates: J. Mat. Sci. 32 (1997) 1249-1259.

4) H. S. Yang, J. Wang, B. L. Shen, H. H. Liu, S. J. Gao and S. J. Huang: Wear 261 (2006) 1150-1154.

5) C. P. Tabrett, I. R. Sare and M. R. Ghomashchi: Int. Mater. Rev. 41 (1996) 2, 59-82.

6) A. Sawamoto, K. Ogi and K. Matsuda: AFS Trans. 94 (1986) 403-416.

7) P. Dupin and J. M. Schissler: AFS Trans. 92 (1984) 355-360.

8) C. R. Loper and H. K. Baik: AFS Trans. 97 (1989) 1001-1008.

9) A. Sawamoto, K. Ogi and K. Matsuda: J. Jpn. Inst. Metals 49 (1985) $475-482$.

10) H. K. Baik and C. R. Loper: AFS Trans. 96 (1988) 405-412.

11) M. Fiset, K. Peev and M. Radulovic: J. Mater. Sci. Lett. 12 (1993) $615-617$.

12) A. Bedolla-Jacuinde: Int. J. Cast Metals Res. 13 (2001) 343-361.

13) M. Filipovic, Z. Kamberovic and M. Korac: J. Metall. 14 (2008) 243-252.

14) M. Radulovic, M. Fiset, K. Peev and M. Tomovic: J. Mater. Sci. 29 (1994) 5085-5094.

15) A. Wiengmoon, T. Chairuangsri, A. Brown, R. Brydson, D. V. Edmonds and J. T. H. Pearce: Acta Mater. 53 (2005) 4143-4154.

16) J. Wang, R. L. Zuo, Z. P. Sun, C. Li, K. K. Liu, H. S. Yang, B. L. Shen and S. J. Huang: Mater. Charact. 55 (2005) 234-240.

17) A. Bedolla-Jacuinde, R. Correa, J. G. Quezada and C. Maldonado: Mater. Sci. Eng. A 398 (2005) 297-308.

18) H. Fushend and W. Chaochang: J. Mater. Sci. Techol. 5 (1989) 918924.

19) J. Durnin and K. A. Ridal: J. Iron Steel Inst. 206 (1968) 60-67.

20) C. Kim: J. Heat. Treat. 1 (1979) 2, 43-51. 